\title{
Poly(ethylene glycol) Doubly and Singly Cationized by Different Alkali Metal Ions: Relative Cation Affinities and Cation- Dependent Resolution in a Quadrupole Ion Trap Mass Spectrometer
}

\author{
Michael J. Bogan and George R. Agnes \\ Department of Chemistry, Simon Fraser University, Burnaby, British Columbia, Canada
}

\begin{abstract}
Structural information of gas phase complexes of poly(ethylene glycol) (PEG) cationized by one or two different alkali metal ions is inferred from MS and MS/MS experiments performed with an electrospray quadrupole ion trap mass spectrometer. The rationale for selecting PEG was that its sites for cation binding are non-selective with respect to the repeating monomeric unit of the polymer, but there is selectivity with respect to the formation of an inner coordination sphere specific to each metal ion. The dissociation of $\left[\mathrm{M}_{1}^{+} \mathrm{M}_{2}^{+}\right.$(EO23)], where $\mathrm{EO} 23$ = linear polymer of ethylene oxide, 23 units in length, resulted in loss of one of the alkali metal ions, with preference for loss of the larger cation, with no fragmentation of the PEG backbone for $\mathrm{Na}, \mathrm{K}, \mathrm{Rb}$, and $\mathrm{Cs}$. Li was not examined in this portion of the study. The selectivity for loss of the larger alkali metal ion was $\left[\mathrm{Na}^{+} \mathrm{K}^{+}\right.$(EO23)] to $\left[\mathrm{Na}^{+}(\mathrm{EO} 23)\right]+\mathrm{K}^{+}$ at $100 \%$; $\left[\mathrm{K}^{+} \mathrm{Rb}^{+}\right.$(EO23)] to $\left[\mathrm{K}^{+}(\mathrm{EO} 23)\right]+\mathrm{Rb}^{+}$at $93 \%$; and $\left[\mathrm{Rb}^{+} \mathrm{Cs}^{+}(\mathrm{EO} 23)\right]$ to $\left[\mathrm{Rb}^{+}(\mathrm{EO} 23)\right]$ $+\mathrm{Cs}^{+}$at $99 \%$. The resolution of $\left[\mathrm{M}^{+}(\mathrm{EO} x)\right]$ for $x=20-30$ was dependent on the alkali metal ion, with the highest resolution observed for $\mathrm{Cs}^{+}$and the lowest for $\mathrm{Na}^{+}$. These results are discussed with respect to the packing of the oxygen atoms on PEG $\left(\mathrm{M} . W_{\cdot} \cdot{ }_{\text {avg }}=1000\right)$ around an alkali metal ion of different radius, and how this packing leads to an ensemble of unique structures, and therefore mobilities for $\left[\mathrm{M}^{+}(\mathrm{EO} x)\right]$. (J Am Soc Mass Spectrom 2002, 13, 177-186) ( 2002 American Society for Mass Spectrometry
\end{abstract}

$\mathrm{E}$ xtensive solution and gas phase investigations of alkali metal ion cationization of small podands, which are linear or ring structures with repeating (-Carbon-Carbon-Heteroatom-) units, have lead to improved understandings of host-guest complexation [1-20]. Factors involved in the solution phase molecular recognition are solvation enthalpy and entropy for both species and the number of atoms from the ligand that are involved with the binding of the metal ion, plus any conformational change of the ligand between its unbound and bound forms [21]. The intrinsic properties of the ion-dipole bonds in these non-covalent complexes are being deduced using a variety of gas phase techniques, including the equilibrium method [22], threshold CID [23-26], and ion chromatography [27, 28].

The long chain podands have received comparatively less attention by mass spectrometry [29, 30], yet their industrial usage is immense, ranging from the fabrication of materials with varied properties to their

Published online December 6, 2001

Address reprint requests to Dr. G. R. Agnes, Department of Chemistry, Simon Fraser University, Burnaby, B.C. V5A 1S6, Canada. E-mail: gagnes@sfu.ca use as phase transfer catalysts in industrial processes [31]. Long chain podands are also used as agents for improving bio-compatibility in immunological applications [32-34] and as ion channel models [35]. Improved knowledge of the structures formed when long chain podands coordinate with alkali metal ions, and particularly with the ubiquitous $\mathrm{Na}^{+}$and $\mathrm{K}^{+}$, can be of use in improving the applications of these materials.

Here we report the uni-molecular dissociation of modest length podands $\left(\right.$ PEG, M.W. $\left.\cdot_{\text {avg }}=1000\right)$ that were doubly cationized by different alkali metal ions. These complexes are abbreviated as $\left[\mathrm{M}_{1}^{+} \mathrm{M}_{2}^{+}(\mathrm{EO} x)\right]$, where $\mathrm{M}_{1}^{+}$and $\mathrm{M}_{2}^{+}$are different alkali metal ions, $\mathrm{EO}=$ ethylene oxide unit, and $x=$ degree of polymerization. This study of the doubly cationized PEG has permitted an in situ measure of the relative binding strength of the cumulative ion-dipole bonds when a single PEG molecule coordinates to the s-orbital of two different alkali metal ions.

The dissociation of these complexes inside a quadrupole ion trap is a form of the kinetic method [36, 37]. In this variation, rather than sandwiching a single cation between two ligands, a single ligand that was large enough to bind two different metal ions was 
used. In an electrospray (ES) quadrupole ion trap mass spectrometry experiment, energy deposition into an ion to cause collision activated dissociation (CAD) can be brought about by adjusting the DC potential on the nozzle-skimmer electrodes of a differentially pumped interface $[38,39]$, or within the trap, collisional quenching of kinetic energy [40], resonance excitation [41, 42], heated bath gas [43], boundary excitation [44], surface collision [45], and photo-dissociation [46] can be employed. In this work, resonance excitation was used to excite a precursor ion, either during a CAD scan function or an ion acquisition scan function (forward scan [47]). The difficulty encountered in this work was that a product ion $\left(\left[\mathrm{M}_{1}^{+}(\mathrm{EO} 23)\right]\right)$ was generated by CAD during the ion acquisition scan that had a higher $\mathrm{m} / \mathrm{z}$ than its precursor ion $\left(\left[\mathrm{M}_{1}^{+} \mathrm{M}_{2}^{+}(\mathrm{EO} 23)\right]\right)$, meaning that these product ions had stable trajectories when the precursor ion did not.

\section{Experimental}

A quadrupole ion trap mass spectrometer (model 3DQ, Teledyne) was fitted with an in-house constructed Electrospray (ES) ion source and a two stage atmospheric pressure gas sampling interface. The emitter for the ES ion source was a stainless steel capillary of dimensions $0.1 \mathrm{~mm}$ i.d. and $0.2 \mathrm{~mm}$ o.d. This capillary was biased to $2800 \mathrm{~V}$ (model PS350, Stanford Research Systems, Sunnyvale, CA, USA). The current passing through this power supply was monitored to ensure the absence of a discharge while data was being collected. The tip of this capillary was positioned $\sim 10 \mathrm{~mm}$ from the counter electrode, which was biased to $300 \mathrm{~V}$. The sample solution was delivered to the ES ion source at $5 \mu \mathrm{l} / \mathrm{min}$. (syringe pump, model 22, Harvard Apparatus, Saint Laurent, Quebec, Canada). Tubing connections between the syringe and the ES capillary were made with standard liquid chromatography fittings. The base pressure of the mass spectrometer with no He added was $5 \times 10^{-5}$ torr measured with an ion gauge calibrated for $\mathrm{N}_{2}$ (model 342, Granville Phillips, Boulder, CO, USA). The operating pressure for the ion trap was set to a corrected pressure of $2 \times 10^{-3}$ torr, by adding $\mathrm{He}$ through a leak valve.

Ions at atmospheric pressure were sampled first through a $75 \mu \mathrm{m}$ diameter orifice into a $\sim 1$ torr zone that was $10 \mathrm{~mm}$ long, and then through a second orifice that was $300 \mu \mathrm{m}$ in diameter. Ions passing through the second orifice were gated into the ion trap by the split middle electrode of an Einzel lens. Ion integration periods of up to $1 \mathrm{~s}$ were used with a constant RF amplitude corresponding to a $\mathrm{m} / \mathrm{z}$ cutoff value ranging from 30-55 Da depending on the experiment and sample solutions [40,48,49]. The amplitude of the RF was subsequently raised to bring the $q$-parameter for the ion of interest to a value in the range 0.3-0.4.

The MS/MS software and electronics package bun- dled with this ion trap was used to isolate an ion population $[50,51]$ and to extend the $m / z$ range $[52,53]$ of the instrument. Access to the MS/MS functionality of the instrument was through a graphical interface that allowed the user to program any combination of sine waves in the range $10-500 \mathrm{kHz}$ at $1 \mathrm{kHz}$ intervals, with the amplitude of each sine wave selectable in the range $0-10 \mathrm{~V}_{p-p}$. When more than one sine wave was selected in an ion isolation waveform, the actual amplitude of each sine wave was equal to the user selectable amplitude divided by the number of sine waves selected. This limitation of the electronics restricted the range of $\mathrm{m} / \mathrm{z}$ that could be isolated using a single waveform.

The extension of the $m / z$ range of the instrument for this work was achieved using a dipolar AC signal at $120.7 \mathrm{kHz}$ and $3 \mathrm{~V}_{p-p}$ on the endcaps during ion acquisition. Used in this way, the mass range of the ion trap was extended to $1500 \mathrm{Da}$, and the RF scan rate for ion acquisition was $2400 \mathrm{Da} \mathrm{s}^{-1}$. Calibration of the $m / z$ axis for the extended $m / z$ range was performed initially by verifying the isolation of an ion whose $m / z$ was less than $650 \mathrm{Da}$ using the normal scan function for the ion trap (mass range $0-650 \mathrm{Da}$, scan rate $=12,000 \mathrm{Da} \mathrm{s}^{-1}$ ). This facilitated the placement of that ion on the extended mass range. Rhodamine 6G was first used for this, and then a PEG molecule doubly cationized by $\mathrm{Na}^{+}$was isolated. Following this, the distribution of polymer molecular weights present in a commercial sample of PEG, M.W.avg. $=1000$ enabled calibration of the $m / z$ axis for the entire spectrum, using both the doubly and singly cationized PEG ions. The mass spectra shown are the average of 10 replicates. All values reported for mass resolution were calculated from $\mathrm{M} / \Delta \mathrm{m}$ where $\Delta \mathrm{m}$ was measured at full width half maximum (FWHM).

Sample solutions consisted of one or more alkali metal ions plus one of the average molecular weight fractions of PEG, either 400,600, 1000, or $1450 \mathrm{~g} \mathrm{~mol}^{-1}$. Ammonium ion, present as an impurity in reagent grade methanol [54] competed with the uptake of $\mathrm{Li}$, and for this reason, the hydroxide salts of $\mathrm{Li}, \mathrm{Na}$, and $\mathrm{K}$ were used for several of the metal ion uptake experiments, otherwise, the reagent grade chloride salts of $\mathrm{Na}$, $\mathrm{K}, \mathrm{Rb}$, and $\mathrm{Cs}$ were used. A minimum mole ratio of total metal ion to PEG was set at 10:1 to ensure the starting solution was under thermodynamic conditions [13] to minimize kinetic [55] and/or solute clustering [56, 57] contributions to the sampled ion population. The sample preparation procedure was simply to dissolve the salts with a minimum of distilled deionized water, and then diluting with reagent grade methanol. The sample solutions used in this work thus contained 1-3\% water. Our in-house constructed atmospheric pressure ion sampling interface has a low ion transmission efficiency, and this necessitated the use of starting solutions containing high $(\mathrm{mM})$ concentrations of metal ion. The PEG samples were purchased from Sigma, and the Rhodamine 6G sample from Exciton. 


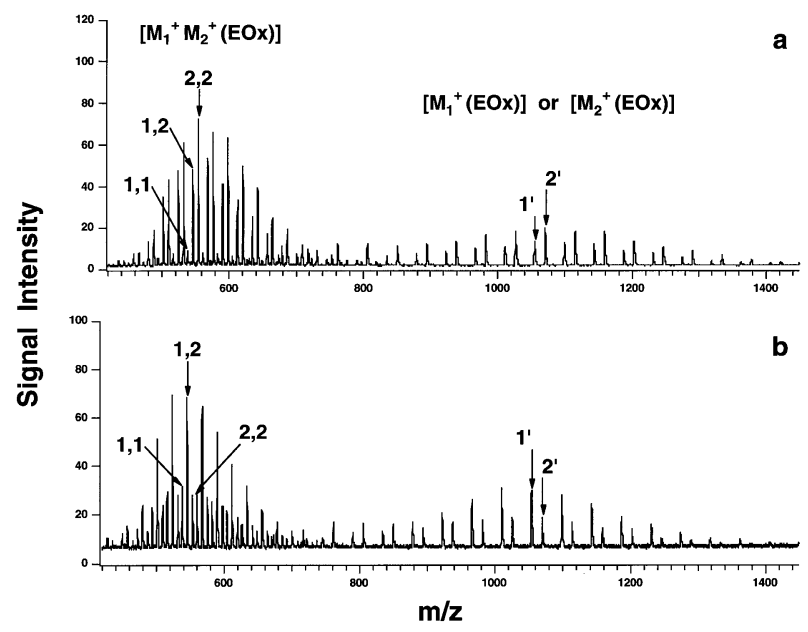

Figure 1. ES mass spectra of PEG M.W. 1000 doubly and singly cationized by $\mathrm{Na}^{+}$and $\mathrm{K}^{+}$. The doubly cationized EO23 are indicated as [1,1], [1,2], and [2,2], and the singly cationized peaks are indicated as [1'] and [2'] with $\mathrm{Na}^{+}$and $\mathrm{K}^{+}$defined respectively as 1 and 2. (a) $\mathrm{Na}^{+}$and $\mathrm{K}^{+}$were equimolar at $1 \mathrm{mM}$, and (b) the $\left[\mathrm{Na}^{+}\right]$was $1 \mathrm{mM}$ and $\left[\mathrm{K}^{+}\right]$was $0.25 \mathrm{mM}$.

\section{Results}

\section{Preparation and Isolation of $\left[M_{1}^{+} M_{2}^{+}\right.$(EO23)]}

The ES-MS spectrum of a solution consisting of equimolar $(1 \mathrm{mM}) \mathrm{Na}^{+}$and $\mathrm{K}^{+}$plus $0.1 \mathrm{mM} \mathrm{PEG} \mathrm{(M.W.avg.}$ $1000)$ is shown in Figure 1a. The ions of the 23 monomer long PEG molecule (EO23) cationized by two $\mathrm{Na}^{+}$, one $\mathrm{Na}^{+}$and one $\mathrm{K}^{+}$, and two $\mathrm{K}^{+}$are indicated. The singly cationized distributions of PEG are readily distinguished from the doubly cationized PEG.

The ion of interest, $\left[\mathrm{Na}^{+} \mathrm{K}^{+}\right.$(EO23)], was isolated using two resonance ejection waveforms applied sequentially. The first waveform contained sine waves whose frequencies corresponded to the secular frequencies of the doubly cationized PEG, with a 1-3 kHz-wide notch for the ion of interest. The second waveform contained sine waves whose frequencies corresponded to the secular frequencies of the singly cationized PEG. Applying these two waveforms in reverse resulted in spectra that exhibited poor isolation for the singly cationized PEG. This suggested that dissociation of $\left[\mathrm{M}_{1}^{+}\right.$ $\left.\mathrm{M}_{2}^{+}(\mathrm{EO} x)\right]$ was facile, and it will be shown in the next section that the fragmentation products were $\left[\mathrm{M}_{1}^{+}\right.$ $(\mathrm{EO} x)]+\mathrm{M}_{2}^{+}$.

The facile fragmentation for the doubly cationized PEG (M.W.avg. $=1000)$ during ion acquisition precluded quantitative measurement of the solution phase abundance of the PEG under the instrumental conditions used. For this reason, a quantitative measure of the alkali metal ion uptake efficiency was made using PEG M.W.avg $=400$ and 600, because Wong and Fenn had suggested in a early ES-MS publication that EO $x$ with $x=5-19$ would not coordinate two alkali metal ions [30]. Two sets of uptake competition experiments were performed, one involving $\mathrm{K}^{+}$plus one other alkali metal ion in the sample solution, and the second set of experiments were conducted with each of the alkali metal ions added to the sample solution. In all cases, the concentration of each alkali metal ion was $1 \mathrm{mM}$ and the uptake efficiency relative to $\mathrm{K}^{+}$has been reported in Table 1. Due to spectral overlaps in the latter experiment, the overall abundance of each complex $\left(\left[\mathrm{M}^{+}\right.\right.$ $(\mathrm{EO} x)]$ ) was calculated using the intensity of the most abundant isotope of $\mathrm{M}^{+}$and then correcting for its stable isotope distribution. No ion peaks corresponding to a solvated cluster were observed.

It was noted early in our work that the trapping potential well depth for the injection of ions [40] into the trap from our API interface did influence the relative uptake efficiency for any given value of $x$ in $\left[\mathrm{M}^{+}(\mathrm{EO} x)\right]$. On our instrument, the trapping potential well depth could only be set to a fixed value during integration of the ion beam, or ion accumulation in the trap. The variation in measured ion abundance as a function of the trapping potential well depth is a mass bias. The well depths used were set using the software as RF

Table 1. Solution phase uptake efficiencies, relative to $\mathrm{K}^{+}(=1)$ for the indicated degree of polymerization of PEG in solutions consisting of equimolar bi - or penta-alkali metal ion combinations plus PEG or M.W. $=400$ or 600

\begin{tabular}{lcccc}
\hline & $\mathrm{Li}$ & $\mathrm{Na}$ & $\mathrm{Rb}$ & $\mathrm{Cs}$ \\
\hline \hline EO5 & & & & \\
$\quad$ Binary & $3.5(1.6)^{\mathrm{a}}$ & $0.9(0.3)$ & $1.3(0.5)$ & $0.7(0.2)$ \\
$\quad$ Multi & $0.2(0.2)$ & $0.9(0.3)$ & $0.9(0.2)$ & $0.3(0.05)$ \\
EO6 & $0.95(0.05)$ & $0.7(0.2)$ & $1.8(0.6)$ & $0.5(0.1)$ \\
$\quad$ Binary & $0.03(0.03)$ & $0.5(0.14)$ & $1.2(0.3)$ & $0.4(0.2)$ \\
$\quad$ Multi & $0.2(0.03)$ & $0.3(0.06)$ & $0.8(0.1)$ & $0.3(0.04)$ \\
EO7-EO12 & $*$ & $0.2(0.05)$ & $0.8(0.14)$ & $0.2(0.04)$ \\
$\quad$ Binary & $*$ & $0.23(0.06)$ & $1.0(0.2)$ & $0.5(0.1)$ \\
$\quad$ Multi & - & - & - & - \\
EO13-EO19 & Binary & & & \\
Multi & & & & \\
\hline
\end{tabular}

aThe value in parentheses is the standard deviation for the relative uptake efficiency, determined from the ion peak height from five replicate mass spectra at each of four different RF cutoffs.

*The peak height for the lithiated complex was not discernable from the baseline noise. The resolution of our instrument for the extended $m / z$ range was insufficient to resolve the peak heights of $\left[\mathrm{M}_{1}^{+} \mathrm{EO}_{x}\right], x=13-19$ for the multi-alkali metal ion sample, and these results are not reported as a result. 


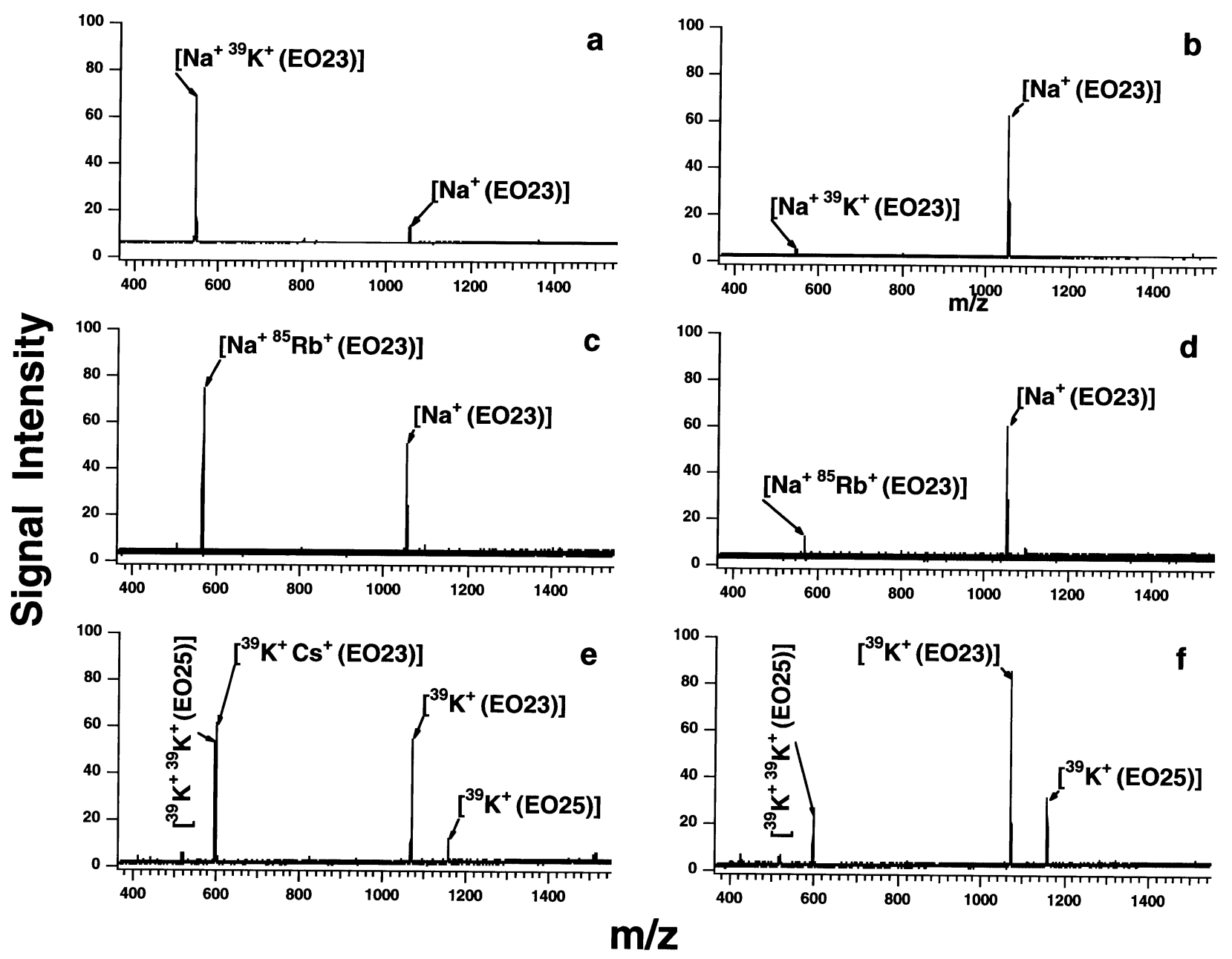

Figure 2. Isolation and fragmentation spectra of EO23 doubly cationized by $\mathrm{Na}^{+}$and $\mathrm{K}^{+}$in (a) and (b), $\mathrm{Na}^{+}$and $\mathrm{Rb}^{+}$in (c) and (d), $\mathrm{K}^{+}$and $\mathrm{Cs}^{+}$in (e) and (f), respectively.

cutoffs, where an RF cutoff of 30 corresponds to an ion of $m / z=30$ having a qvalue of 0.908 . The RF cutoffs used during ion integration were $30,35,40$, and 55 , and the average uptake ratio from these four different RF cutoffs has been reported in Table 1 .

Examination of the relative uptake efficiency for $\mathrm{Na}^{+}$ versus $\mathrm{K}^{+}$, for EO13-EO19, indicates that in order to maximize the abundance of $\left[\mathrm{Na}^{+} \mathrm{K}^{+}(\mathrm{EO} x)\right]$ with $x=$ $20-30$, the mole ratio of $\mathrm{Na}$ to $\mathrm{K}$ in the sample solution should be $\sim 4: 1$. A sample solution was then prepared with $\mathrm{Na}^{+}$at $1 \mathrm{mM}, \mathrm{K}^{+}$at $0.25 \mathrm{mM}$ and PEG (M.W.avg $=$ $1000)$ at $0.1 \mathrm{mM}$, and this sample yielded the spectrum displayed in Figure $1 \mathrm{~b}$. The abundance of $\left[\mathrm{Na}^{+} \mathrm{K}^{+}\right.$ $(E O x)]$ clearly exceeded the abundance of either $\left[\mathrm{Na}^{+}\right.$ $\left.\mathrm{Na}^{+}(\mathrm{EO} x)\right]$ or $\left[\mathrm{K}^{+} \mathrm{K}^{+}(\mathrm{EO} x)\right]$. This procedure was used to prepare a maximized abundance of doubly cationized PEG (M.W. = 1000) for each combination of alkali metal ions, and the success of this approach suggests that multiple alkali metal ion uptake by long chain podands can be estimated from the uptake efficiency for single metal ions by EOx with $x=13-19$.

\section{Gas Phase Dissociation of $\left[M_{1}^{+} M_{2}^{+}\right.$(EO23)]}

The spectra shown in Figure 2 and Figure 3 show the isolated and dissociated doubly cationized PEG molecule for the respective cases of a relatively large and small size difference between the two alkali metal ions. It will be shown that the fragmentation of doubly cationized PEG involving simple loss of one metal ion correlates well with their ionic radii, where the smaller cation has the higher relative affinity (stronger Lewis acid) for the PEG backbone. The crystal radius of the alkali metal ions are $\mathrm{Na}^{+}=102, \mathrm{~K}^{+}=138, \mathrm{Rb}^{+}=149$, and $\mathrm{Cs}^{+}=170 \mathrm{pm}$.

Figure 2a shows the isolation spectrum for $\mathrm{EO} 23$ doubly cationized by $\mathrm{Na}^{+}$and $\mathrm{K}^{+}$. The isolation of this ion, $\left[\mathrm{Na}^{+} \mathrm{K}^{+}\right.$(EO23)], was greatly facilitated by the fact that the homo $\left(\left[\mathrm{Na}^{+} \mathrm{Na}^{+}(\mathrm{EO} x)\right],\left[\mathrm{K}^{+} \mathrm{K}^{+}(\mathrm{EO} x)\right]\right)$, and hetero cationized PEG $\left(\left[\mathrm{Na}^{+} \mathrm{K}^{+}(\mathrm{EO} x)\right]\right)$ were baseline resolved. The one fragment ion observed in the isolation spectrum, $\left[\mathrm{Na}^{+}\right.$(EO23)], was not a function of inefficient isolation of the precursor ion. This was verified by isolating $\left[\mathrm{Na}^{+} \mathrm{K}^{+}\right.$(EO23)] and then setting 


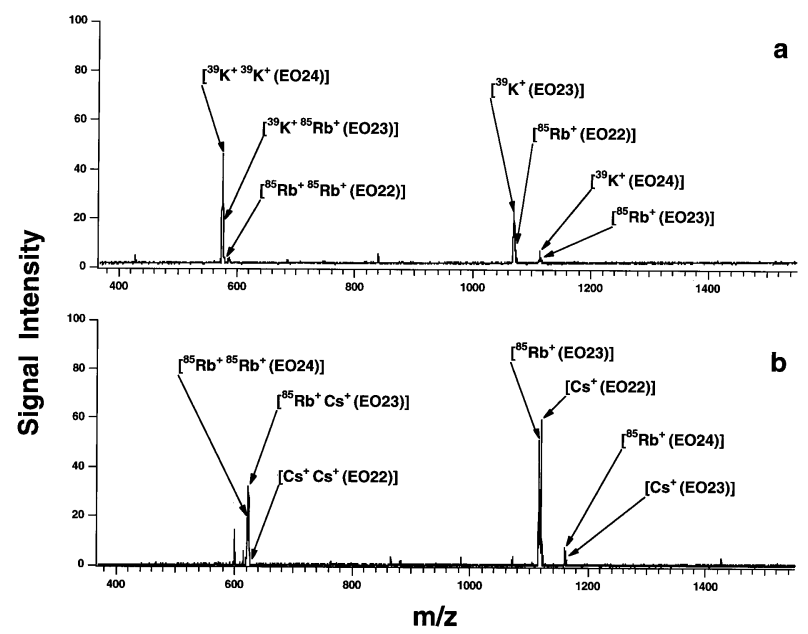

Figure 3. Isolation spectra of EO23 doubly cationized by (a) $\mathrm{K}^{+}$ and $\mathrm{Rb}^{+}$and (b) $\mathrm{Rb}^{+}$and $\mathrm{Cs}^{+}$.

the ion acquisition scan to read out only ions whose $\mathrm{m} / \mathrm{z}$ were in the range 700-1500 Da. For such scans, there were no ions detected. This led us to conclude that for acquisition scans where the precursor ion was resonantly excited by the external AC field during ejection from the trap [58], a measurable fraction of that population fragmented while it was still inside the trap. The extent to which this precursor ion fragments because of resonance excitation during ion acquisition was found to be dependent on the relative cation affinity of the cation whose affinity to EO23 was weaker, as discussed below.

For example, in Figure 2a, although there was no CAD scan function used, the intensity of the precursor ion was inflated. Following isolation, $\left[\mathrm{Na}^{+} \mathrm{K}^{+}\right.$(EO23)] was resonantly excited to high amplitudes of motion by the external AC field during the ion acquisition scan. At this instant of time in the ion acquisition scan, the amplitude of the RF applied to the ring electrodes was $1670 \mathrm{~V}_{o-p}$ and the $q$-value of $\left[\mathrm{Na}^{+} \mathrm{K}^{+}(\mathrm{EO} 23)\right]$ was 0.366 . A fraction of the $\left[\mathrm{Na}^{+} \mathrm{K}^{+}\right.$(EO23)] population underwent $\mathrm{CAD}$ while still inside the ion trap, producing $\left[\mathrm{Na}^{+}(\mathrm{EO} 23)\right]$ and $\left[\mathrm{K}^{+}\right]$at equal abundance. The $q-$ values of these product ions at this instant of the ion acquisition scan were 0.190 and 5.12 respectively. $\mathrm{K}^{+}$ had an unstable $q$-value and it was ejected simultaneously with intact precursor ions. However, $\left[\mathrm{Na}^{+}\right.$ (EO23)] was stable inside the trap and it was not resonantly ejected until later in the ion acquisition scan, when the RF amplitude had increased such that this ion's secular frequency came into resonance with the external AC field. Therefore, the intensity of the signal corresponding to the precursor ion in Figure 2a is the summation of two ions, the precursor ion itself ([ $\mathrm{Na}^{+}$ $\mathrm{K}^{+}$(EO23)]) and one of its fragments, $\mathrm{K}^{+}$. The intensity of the $\mathrm{K}^{+}$should be equal to the intensity of the other fragment ion $\left[\mathrm{Na}^{+}\right.$(EO23)] assuming no difference in the efficiency of detecting these two ions, and the remaining signal due to intact precursor ions ejected from the trap.
When an additional scan function to purposely cause CAD of the precursor ion $\left[\mathrm{Na}^{+} \mathrm{K}^{+}\right.$(EO23)] by resonance excitation was applied, there was an increased abundance of the one single fragment ion detected $\left(\left[\mathrm{Na}^{+}(\mathrm{EO} 23)\right]\right)$ (Figure 2b). This spectrum illustrates the very high selectivity that $\mathrm{EO} 23$ had for $\mathrm{Na}^{+}$relative to $\mathrm{K}^{+}$.

Figure 2c shows the spectrum obtained when $\left[\mathrm{Na}^{+}\right.$ $\mathrm{Rb}^{+}$(EO23)] was isolated. Based on relative peak heights, the precursor ion $\left[\mathrm{Na}^{+} \mathrm{K}^{+}\right.$(EO23)] (Figure 2a) exhibited a lower degree of fragmentation during an ion acquisition scan than $\operatorname{did}\left[\mathrm{Na}^{+} \mathrm{Rb}^{+}\right.$(EO23)] (Figure 2c). This suggested that the $\mathrm{Rb}^{+}$was bound less tightly by the ligand, and its loss was more facile relative to $\mathrm{K}^{+}$. The fragmentation of $\left[\mathrm{Na}^{+} \mathrm{Rb}^{+}\right.$(EO23)] also yielded accessibility to one dissociation channel, yielding $\left[\mathrm{Na}^{+}\right.$ (EO23)] and $\mathrm{Rb}^{+}$(Figure 2d). $\mathrm{Rb}^{+}$was not detected because $q_{\mathrm{Rb}+}>0.908$ during the MS/MS events, and no attempt was made to adjust the condition of this CAD experiment to allow for storage of this product ion.

The isolation of the precursor ion $\left[\mathrm{K}^{+} \mathrm{Cs}^{+}\right.$(EO23)] (Figure 2e) was problematic. This precursor ion was only $3 \mathrm{Da}$ heavier than the homo-alkali metal ion doubly cationized EO25, $\left[\mathrm{K}^{+} \mathrm{K}^{+}\right.$(EO25)], at $\mathrm{m} / z=598$. The resolution for isolation of two ions in the ion trap was $\sim 300$ and these two ions were in theory, separable. However, in practice, it was found that to eject all of $\left[\mathrm{K}^{+} \mathrm{K}^{+}(\mathrm{EO} 25)\right]$, the ion of interest $\left(\left[\mathrm{K}^{+} \mathrm{Cs}^{+}(\mathrm{EO} 23)\right]\right)$ fragmented by off-resonance absorption of the external AC field. This result further exemplifies the fragility of each of the doubly cationized precursor ions examined in this work. This practical limitation, plus the low abundance of the precursor ion population before isolation, meant that the attainable resolution for ion isolation was only $\sim 100$. The low solution phase uptake efficiency of $\mathrm{Cs}^{+}$relative to $\mathrm{K}^{+}$by PEG meant that the abundance of $\left[\mathrm{Cs}^{+} \mathrm{Cs}^{+}(\mathrm{EO} 21)\right]$ at $\mathrm{m} / z=604$ was small, otherwise this ion would have been an additional interference on the isolation of $\left[\mathrm{K}^{+} \mathrm{Cs}^{+}\right.$(EO23)].

Fortunately, the possible fragment ions of the two precursor ions isolated in Figure 2e were resolved by the ion acquisition scan. The possible fragment ions were $\left[\mathrm{K}^{+}(\mathrm{EO} 23)\right],\left[\mathrm{Cs}^{+}\right.$(EO23)], and $\left[\mathrm{K}^{+}\right.$(EO25)]. CAD of $\left[\mathrm{K}^{+} \mathrm{Cs}^{+}\right.$(EO23)] lead to only one dissociation channel being accessible in the ion trap MS/MS, producing $\left[\mathrm{K}^{+}(\mathrm{EO} 23)\right]$ and $\mathrm{Cs}^{+}$. The data presented in Figure 2 allowed us to conclude that when the difference in the crystal radius of the adducted alkali metal ions is $\geq 32$ pm, $\left[\mathrm{M}_{1}^{+} \mathrm{M}_{2}^{+}\right.$(EO23)] fragments through simple loss of the larger metal ion only in these ion trap CAD experiments.

The fragmentation of $\left[\mathrm{K}^{+} \mathrm{Rb}^{+}\right.$(EO23)] (Figure 3a) and $\left[\mathrm{Rb}^{+} \mathrm{Cs}^{+}(\mathrm{EO} 23)\right]$ (Figure $3 \mathrm{~b}$ ) involve cations whose difference in radii is $<32 \mathrm{pm}$, and for these precursors, the selectivity for loss of one cation during CAD was lower because two high mass fragment ions were observed. Thus there were two accessible fragmentation channels that differed only by the ligand (EO23) retaining one alkali metal ion over the other. The 


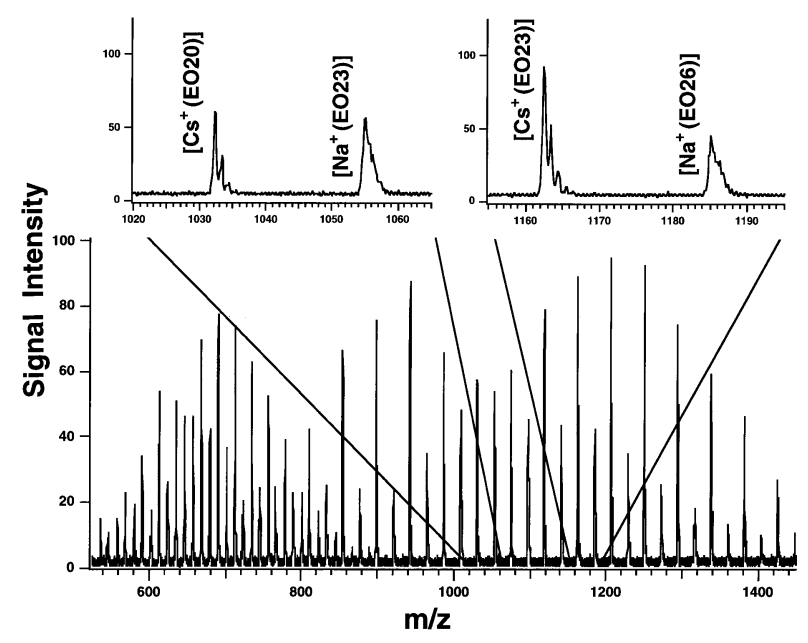

Figure 4. Spectra of PEG M.W. $=1000$ cationized by $\mathrm{Na}^{+}$and/or $\mathrm{Cs}^{+}$. The differential resolution for $\left[\mathrm{M}_{1}^{+}(\mathrm{EO} x)\right]$ is apparent for $\mathrm{M}_{1}^{+}$ $=\mathrm{Na}^{+}$versus $\mathrm{Cs}^{+}$in the two insets.

ligand itself was not fragmented. Because of the relatively large degree of fragmentation of these precursor ions during an acquisition scan, there was no need to include an MS/MS scan. Several precursor ions were present in each window of $\mathrm{m} / \mathrm{z}$ following isolation of the ion of interest. Again, it was fortunate that the product ions of these interfering ions were resolvable by the ion acquisition scan. For example, in Figure 3 a the ion of interest $\left(\left[{ }^{39} \mathrm{~K}^{+}{ }^{85} \mathrm{Rb}^{+}\right.\right.$(EO23)]) at $\mathrm{m} / \mathrm{z}=577$ had two interfering ions within $1 \mathrm{Da},\left[{ }^{39} \mathrm{~K}^{+}{ }^{39} \mathrm{~K}^{+}(\mathrm{EO} 24)\right]$ at $\mathrm{m} / \mathrm{z}$ $=576$ and $\left[{ }^{85} \mathrm{Rb}^{+}{ }^{85} \mathrm{Rb}^{+}\right.$(EO22) $]$at $m / z=578$. The two possible high mass fragment ions from the precursor ion of interest were $\left[{ }^{39} \mathrm{~K}^{+}(\mathrm{EO} 23)\right]^{+}$and $\left[{ }^{85} \mathrm{Rb}^{+}\right.$(EO23)], and their relative abundance was able to be measured from Figure 3a as 93:7. This was the measured selectivity of EO23 for the retention of $\mathrm{K}^{+}$, whose crystal radius is only $11 \mathrm{pm}$ smaller than $\mathrm{Rb}^{+}$.

The isolation of $\left[{ }^{85} \mathrm{Rb}^{+}{ }^{133} \mathrm{Cs}^{+}\right.$(EO23)] also suffered similar interference, and the interfering ions are indicated in Figure 3b. The product ions of interest, $\left[{ }^{85} \mathrm{Rb}^{+}\right.$ (EO23)] and $\left[{ }^{133} \mathrm{Cs}^{+}\right.$(EO23)] were again able to be resolved and these ions had a signal intensity ratio of 99:1. In this case, the selectivity for retention of the smaller cation $\mathrm{Rb}^{+}$was greater because the difference in crystal radius between it and $\mathrm{Cs}^{+}$was $21 \mathrm{pm}$.

\section{Effect of $M_{1}^{+}$on the Resolution of $\left[M_{1}^{+}(E O x)\right]$}

A spectrum obtained from a solution that contained equimolar $\mathrm{Na}$ and $\mathrm{Cs}(1 \mathrm{mM})$ plus $0.1 \mathrm{mM}$ PEG $\left(\mathrm{M} . \mathrm{W}_{\text {avg }}=1000\right)$ is shown in Figure 4.The two insets each show a small section of the singly cationized distribution of PEG, and for these ion peaks, the resolution $(\mathrm{M} / \Delta \mathrm{m})$ for PEG cationized by $\mathrm{Cs}^{+}$was greater, by a factor of $\sim 4$, than those cationized by $\mathrm{Na}^{+}$. The dependence on the metal ion for the resolution of $\left[\mathrm{M}_{1}^{+}\right.$ $(\mathrm{EO} x)]$ versus $\left[\mathrm{M}_{2}^{+}(\mathrm{EO} x)\right]$, where $x=20-30$, was observed in every spectrum recorded in this work, and because these two metal ion PEG complexes were present in the ion trap at the same time, differential instrumental factors between scans that are known to degrade resolution in a Paul trap, such as space charge, RF scan rate, and He pressure, were not relevant.

The FWHM and resolution for doubly and singly cationized PEG for varied degree of polymerization and alkali metal ion are summarized in Table 2. It is apparent that the FWHM for each metal ion complex of EO9 was constant at $\Delta \mathrm{m}=0.44$. This suggests that for short polymer chain lengths, there is only a single conformation of $\left.\left[\mathrm{M}_{1}^{+} \mathrm{EO} x\right)\right]$ because the metal ion $\left(\mathrm{Na}^{+}\right.$, $\mathrm{K}^{+}, \mathrm{Rb}^{+}$, or $\mathrm{Cs}^{+}$) can accommodate all oxygen atoms from the EO9 backbone in its inner coordination sphere.

This situation changed however when the chain length of PEG was increased to 20 or more ethylene oxide units. There exist several observable trends in this data (Table 2). For all of these ions, the FWHM of the peaks for each alkali metal ion is $\geq 0.5$. This suggests that for all of these ions, the resolution measured for these ions was not limited by the instrument, but rather from the nature of the ions themselves. Secondly, the FWHM decreased as the cation size increased. $\left[\mathrm{Na}^{+}\right.$ (EO20)] and $\left[\mathrm{K}^{+}\right.$(EO30)] had FWHM $\geq 1.6$, whereas $\left[\mathrm{Rb}^{+}\right.$(EO20)] and $\left[\mathrm{Cs}^{+}\right.$(EO20)] had FWHM $\leq 0.9$. Thirdly, the FWHM decreased for the $\mathrm{Rb}$ and $\mathrm{Cs}$ complexes $\left(\left[\mathrm{M}_{1}^{+}(\mathrm{EO} x)\right]\right)$ as the degree of polymeriza-

Table 2. Resolution $(\mathrm{M} / \Delta \mathrm{m})$ for ions formed by the complexation of one or two homo-alkali metal ions with PEG with the indicated degree of polymerization

\begin{tabular}{llllllll}
\hline & $\begin{array}{c}{\left[\mathrm{M}_{1}^{+}\right.} \\
(\mathrm{EO9})]^{\mathrm{a}}\end{array}$ & $\begin{array}{c}{\left[\mathrm{M}_{1}^{+} \mathrm{M}_{1}^{+}\right.} \\
(\mathrm{EO} 20)]\end{array}$ & $\begin{array}{c}{\left[\mathrm{M}_{1}^{+} \mathrm{M}_{1}^{+}\right.} \\
(\mathrm{EO30})]\end{array}$ & $\begin{array}{c}{\left[\mathrm{M}_{1}^{+}\right.} \\
(\mathrm{EO} 20)]\end{array}$ & $\begin{array}{c}{\left[\mathrm{M}_{1}^{+}\right.} \\
(\mathrm{EO23})]\end{array}$ & $\begin{array}{c}{\left[\mathrm{M}_{1}^{+}\right.} \\
(\mathrm{EO27})]\end{array}$ & $\begin{array}{c}{\left[\mathrm{M}_{1}^{+}\right.} \\
(\mathrm{EO30})]\end{array}$ \\
\hline \hline $\mathrm{Na}$ & $(437 / 0.49)$ & $(472 / 1.7)$ & $(692 / 2.0)$ & $(921 / 2.13)$ & $(1,053 / 2.8)$ & $(1,229 / 1.8)$ & $(1,361 / 1.8)$ \\
& $=892$ & $=278$ & $=346$ & $=432$ & $=376$ & $=683$ & $=756$ \\
${ }^{39} \mathrm{~K}$ & $(453 / 0.43)$ & $(488 / 1.8)$ & $(708 / 1.4)$ & $(937 / 1.7)$ & $(1,069 / 2.1)$ & $(1,245 / 2.4)$ & $(1,337 / 1.6)$ \\
& $=1,053$ & $=271$ & $=506$ & $=551$ & $=509$ & $=519$ & $=861$ \\
${ }^{85} \mathrm{Rb}$ & $(499 / 0.43)$ & $(534 / 1.7)$ & $(754 / 2.1)$ & $(983 / 0.9)$ & $(1,115 / 0.7)$ & $(1,291 / 0.6)$ & $(1,423 / 0.6)$ \\
& $=1,160$ & $=314$ & $=359$ & $=1,092$ & $=1,593$ & $=2,152$ & $=2,372$ \\
$\mathrm{Cs}$ & $(547 / 0.44)$ & $(582 / 1.4)$ & $(802 / 1.4)$ & $(1,031 / 0.7)$ & $(1,163 / 0.7)$ & $(1,339 / 0.6)$ & $(1,471 / 0.5)$ \\
& $=1,243$ & $=416$ & $=573$ & $=1,473$ & $=1,661$ & $=2,232$ & $=2,942$ \\
\hline
\end{tabular}

${ }^{a}$ The resolution was obtained under normal ion trap operation with mass range to $650 \mathrm{Da}$, all other columns were obtained with the mass range extended to $1,500 \mathrm{Da}$. 
tion, $x$, increased. An explanation for the latter two observations is now offered.

The trend in any one column in Table 2 (for $\left[\mathrm{M}_{1}^{+}\right.$ $(\mathrm{EO} x)], x \geq 20$ ) showing decreased FWHM as the alkali metal ion size increased, was likely a function of the number of distinct conformations of $\left[\mathrm{M}_{1}^{+}(\mathrm{EO} x)\right]$ for any given value of $x$. In the presence of $2 \mathrm{mTorr}$ of He, there was sufficient difference in the mobilities of the conformers for $\left[\mathrm{Na}^{+}(\mathrm{EO} x)\right]$ versus $\left[\mathrm{Cs}^{+}(\mathrm{EO} x)\right]$ for $x=$ 20-30, that a wider peak was consistently measured for $\left[\mathrm{Na}^{+}(\mathrm{EO} x)\right]$. These conformers were only barely separated because the period during which these conformers could have been separated was only a few $\mu$ s of resonance excitation during their ejection from the trap. This explanation for the differential resolution of $\left[\mathrm{Cs}^{+}\right.$ $(\mathrm{EO} x)]$ versus $\left[\mathrm{Na}^{+}(\mathrm{EO} x)\right]$ suggests that an ion mobility experiment inside the ion trap $[59,60]$ may be capable of deducing the actual number of structural isomers of $\left[\mathrm{M}_{1}^{+}(\mathrm{EO} x)\right]$. This interpretation of the data suggests that the resolution for $\left.\left[\mathrm{Cs}^{+} \mathrm{EO} x\right)\right]$ for $x>30$ would likely degrade as the number of conformers for any given value of $x$ was increased.

The explanation for the trend in resolution within any one column of Table 2 is in contradiction to the trend of decreased FWHM across any one row in Table 2 , because as the degree of polymerization increased, so should have the number of conformers and hence a wider FWHM should have been measured. However, the FWHM of these ion peaks either remained invariant $\left(\mathrm{Na}^{+}\right.$and $\left.\mathrm{K}^{+}\right)$, or it decreased $\left(\mathrm{Rb}^{+}\right.$and $\left.\mathrm{Cs}^{+}\right)$across any one row. This contradiction is believed to be the result of two effects, space charge [61] and the number of conformers. Because all ion acquisition scans were made in the forward direction (i.e., low $\mathrm{m} / \mathrm{z}$ ejected first), the degree of space charge for the ejection of $\left[\mathrm{M}_{1}^{+}\right.$ $(\mathrm{EO} x)]$ at low values of $x$ would have been considerably more severe than for the $\left[\mathrm{M}_{1}^{+}(\mathrm{EO} x)\right]$ at high values of $x$ because there would have been fewer ions reside in the trap. For the ejection of $\left[\mathrm{M}_{1}^{+}(\mathrm{EO} x)\right]$ where $x=30$, the dominant factor determining the overall FWHM of that ion cloud was the difference in mobility of the conformers inside the trap. We are presently conducting experiments to test the validity of these explanations.

\section{Discussion}

The efficiency for uptake of an alkali metal ion by PEG is clearly a balance between the solvation of the ion and the capability of the PEG to displace the solvent and coordinate with the cation [21]. This has been reinforced with the determination of the relative intrinsic cation affinities for $\mathrm{Na}, \mathrm{K}, \mathrm{Rb}$, and $\mathrm{Cs}$ for PEG. $\mathrm{Cs}^{+}$being the largest cation (weakest Lewis acid), had the lowest relative affinity, and $\mathrm{Na}^{+}$the smallest cation examined (strongest Lewis acid), had the highest relative affinity.

The solution phase uptake efficiencies of alkali metal ions by EO $x$ for $x=13-19$ in 97:3 methanol:water solutions for $\mathrm{Na}^{+}, \mathrm{K}^{+}, \mathrm{Rb}^{+}$, and $\mathrm{Cs}^{+}$were $0.2,1.0,1.0$, and 0.5 respectively. A previous study of these uptake efficiencies by Chan and Cook, who used electrohydrodynamic ionization, reported uptake efficiencies for $\mathrm{Na}^{+}, \mathrm{K}^{+}, \mathrm{Rb}^{+}$, and $\mathrm{Cs}^{+}$as 0.46, 1.0, 0.79, and 0.94, respectively [62]. In Chan and Cook's work the solvent was glycerol and the value of $x$ ranged from 16-22. There are clearly some interesting effects due to the change in solvent, and possibly the ionization source, but because of the instrumental factors that were encountered in our work (mass bias, fragmentation during ion ejection causing distorted ion abundance), and also in the work from Chan and Cook as documented elsewhere [63, 64], we believe it prudent to not overinterpret and compare these uptake results. We believe that a systematic study of the metal ion uptake efficiencies for different solvent compositions using one instrument, whose operating characteristics have been fully characterized and understood, is necessary before detailed discussion of solution phase molecular recognition by long chain podands can be made. Experiments are being designed in our laboratory to collect this needed data.

Bowers and co-workers measured the collision cross section of $\left[\mathrm{Na}^{+}\right.$(EO9)] and subsequently calculated minimized structures for that ion. These authors reported that the most stable structure calculated for this ion had eight oxygen atoms positioned as nearest neighbors to the $\mathrm{Na}^{+}$[65]. In related work, the same research group calculated that $\mathrm{Cs}^{+}$, with its larger radius, can coordinate 11 oxygen atoms from a PEG molecule [27]. The results from our MS/MS experiments to establish a relative cation affinity to $\mathrm{EO} 23$ clearly indicate that even though there may be an increased number of oxygen atoms surrounding $\mathrm{Cs}^{+}$, the additional ion-dipole bonds do not compensate for the longer bond lengths. Thus, $\mathrm{Cs}^{+}$has a lower relative affinity to PEG than $\mathrm{Na}^{+}$.

With respect to the resolution dependence on the alkali metal ion in resolution for $\left[\mathrm{M}_{1}^{+}(\mathrm{EO} x)\right]$ with $x=$ 20-30, there are several possible explanations. The resolution increased from $\mathrm{Na}^{+}$to $\mathrm{Cs}^{+}$, and this trend correlates negatively with the relative strength with which the metal ion coordinates to EOx. It was suggested to us by an anonymous reviewer that there may be internal or kinetic energy differences between these complexes that lead to the observed trend in resolution. The quenching of kinetic and internal energy of an ion in an ion trap is believed to occur on a timescale of less than $10 \mathrm{~ms}$ [66]. However, Liere et al. [67, 68] reported that the internal energy of a trapped population of ions can be raised at long times $(\sim>60 \mathrm{~ms})$ following a resonance excitation event. A difference in energy between $\left[\mathrm{Na}^{+}(\mathrm{EO} x)\right]$ and $\left[\mathrm{Cs}^{+}(\mathrm{EO} x)\right]$ during the ion acquisition scan may be responsible for the observed differential resolution, because such a difference could influence the structure of an ion or the size of that ion cloud in the ion trap. In our experiments, the time between exciting a fragile precursor ion $\left(\left[\begin{array}{ll}\mathrm{M}_{1}^{+} & \mathrm{M}_{2}^{+}\end{array}\right.\right.$ $(\mathrm{EO} x)]$ ) during the ion acquisition scan (at $2400 \mathrm{Da} \mathrm{s}^{-1}$ ) and then exciting its heavier fragment, $\left[\mathrm{M}_{1}^{+}(\mathrm{EO} x)\right]$, was 
$\sim 200 \mathrm{~ms}$. Based on this delay period, it is difficult to rationalize an argument where there would remain a difference in energy between $\left[\mathrm{Na}^{+}(\mathrm{EO} x)\right]$ and $\left[\mathrm{Cs}^{+}\right.$ $(E O x)]$ sufficient to cause the observed differences in resolution because of helium bath gas quenching [66]. However, we cannot rule out this possibility.

An alternative explanation is that the number of conformers for $\left[\mathrm{M}^{+}(\mathrm{EO} x)\right]$ for any given value of $x$ is dependent specifically on the size of each alkali metal ion, and how each metal ion coordinates to the oxygen atoms in PEG. If eight oxygen atoms encapsulate $\mathrm{Na}^{+}$to form a complete inner coordination sphere [4], the binding of these oxygen atoms set the number of possible conformations for $\left[\mathrm{Na}^{+}\right.$(EO30)] at 12. This estimate neglects the involvement of a secondary coordination sphere and any additional conformations that would result from a loop or bulge in the backbone of EO30 in its coordination to $\mathrm{Na}^{+}$. In comparison, $\left[\mathrm{Cs}^{+}\right.$ (EO30)] would have 10 unique conformations based on the calculations by Wyttenbach who suggested that 11 oxygen atoms from PEG coordinate to $\mathrm{Cs}^{+}$[27]. If however, the eight oxygen atoms that were calculated to coordinate with $\mathrm{Na}^{+}$define a packing density around an alkali metal ion [65], then $\mathrm{Cs}^{+}$could accommodate as many as $\sim 22$ oxygen atoms from PEG based on surface area alone. If this estimate does approximate the real coordination of $\mathrm{Cs}^{+}$to $\mathrm{PEG}$, then in $\left[\mathrm{Cs}^{+}(\mathrm{EO} 30)\right]$ there could be as few as four conformers. Again, these estimates neglect loops or bulges in the ligand when it wraps around the cation. The actual number of conformations for any given ion population $\left[\mathrm{M}_{1}^{+}(\mathrm{EO} x)\right]$ remains to be experimentally verified using an ion mobility spectrometer [69-71], or performing an ion mobility experiment in an ion trap [60].

\section{Conclusions}

The relative cation affinity for the binding of a second alkali metal ion to PEG, for degree of polymerization equal to 23 ethylene oxide units, has been established through CAD of $\left[\mathrm{M}_{1}^{+} \mathrm{M}_{2}^{+}(\mathrm{EO} x)\right]$ in an ion trap. An unexpectedly large difference in resolution for $\left[\mathrm{M}_{1}^{+}\right.$ $(\mathrm{EO} x)$ ] with $x=20-30$ was observed, where the resolution increased with increased cation size. This observation is likely related to the number of conformers of these ions, and ultimately the mobility of these conformers in a quadrupole ion trap mass spectrometer. We are in the process of delineating the underlying causes of these observations for these alkali metal ion-PEG complexes with respect to properties of the ion (polymer type, length, and cation) and also with respect to the operating parameters of the ion trap.

\section{Acknowledgments}

MJB is grateful for support from an undergraduate NSERC fellowship. This work was funded by the Natural Science and Engineering Research Council of Canada.

\section{References}

1. Gokel, G. W.; Murillo, O. Podants. Gokel, G. W., Ed. Molecular Recognition: Receptors for Cationic Guests, Vol. I of Comprehensive Supramolecular Chemistry. Elsevier Sci.: New York, 1996; 1-33.

2. Reyzer, M. L.; Brodbelt, J. S.; Marchand, A. P.; Chen, Z.; Hunag, Z.; Namboothiri, I. N. N. Determination of Ligand Binding Selectivities of Caged Crown Ligands by Electrospray Ionization Quadrupole Ion Trap Mass Spectrometry. Int. J. Mass Spectrom. 2001, 204, 133-142.

3. Blair, S. M.; Brodbelt, J. S.; Marchand, A. P.; Kumar, K. A.; Chong, H.-S. Evaluation of Binding Selectivities of Caged Ligands Toward Heavy Metals by Electrospray Ionization/ Quadrupole Ion Trap Mass Spectrometry. Anal. Chem. 2000, 73, 2433-2445.

4. Gidden, J.; Wyttenbach, T.; Jackson, A. T.; Scrivens, J. H.; Bowers, M. T. Gas Phase Conformations of Synthetic Polymers: Poly(ethylene glycol), Poly(propylene glycol), and Poly(tetramethylene glycol). J. Am. Soc. Chem. 2000, 122, 4692-4699.

5. Kempen, E. C.; Brodbelt, J. S. A Method for the Determination of Binding Constants by Electrospray Ionization Mass Spectrometry. Anal. Chem. 2000, 72, 5411-5416.

6. Shen, N.; Pope, R. M.; Dearden, D. V. Fundamental Factors Controlling the Exchange of Multidentate Ligand: Displacement of 12-Crown-4 and Triglyme from Complexes with Divalent Alkaline Earth Cations. Int. J. Mass Spectrom. 2000, 195/196, 639-652.

7. Bartoszek, M.; Graubaum, H.; Wendland, D.; Dambowski, R. Investigation of Metal-Ion Complexes of Triazino Crown Ethers with Podand Arms by Electrospray Ionization. Eur. Mass Spectrom. 1999, 5, 81-88.

8. Brodbelt, J. S.; Kempen, E. C.; Reyzer, M. L. Determination of Binding Selectivities by Electrospray Ionization Mass Spectrometry. Struct. Chem. 1999, 10, 213-220.

9. Kempen, E. C.; Brodbelt, J. S.; Bartsch, R. A.; Jang, Y.; Kim, J. S. Investigation of Alkali Metal Cation Selectivities of Lariat Ethers by Electrospray Ionization Mass Spectrometry. Anal. Chem. 1999, 71, 5493-5500.

10. Blair, S. M.; Brodbelt, J. S.; Reddy, G. M.; Marchand, A. P. Evaluation of Binding Selectivities of Bis-Crowned Clefts by Electrospray Ionization/Quadrupole ion Trap Mass Spectrometry. J. Mass Spectrom. 1998, 33, 721-728.

11. Young, D.-S.; Hung, H.-Y.; Liu, L. K. An Easy and Rapid Method for Determination of Stability Constants by Electrospray Ionization Mass Spectrometry. Rapid Commun. Mass Spectrom. 1997, 11, 769-773.

12. Young, D.-S.; Hung, H.-Y.; Liu, L. K. Estimation of Selectivities and Relative Cationization Efficiencies of Different [crown + M]+ by Electrospray Mass Spectrometry. J. Mass Spectrom. 1997, 32, 432-437.

13. Leize, E.; Jaffrezic, A.; Dorsseler, A. V. Correlation Between Solvation Energies and Electrospray Mass Spectrometry Response Factors: Study by Electrospray Mass Spectrometry of Supramolecular Complexes in Thermodynamic Equilibrium in Solution. J. Mass Spectrom. 1996, 31, 537-544.

14. Wang, K.; Gokel, G. W. The Use of Mass Spectrometry to Assess Complexation Phenomena in Receptor Compounds. Pure \& Appl. Chem. 1996, 68, 1267-1272.

15. Hay, B. P.; Rustad, J. R.; Hostetler, C. J. Quantitative StructureStability Relationship for Potassium Ion Complexation by Crown Ethers: A Molecular Mechanics and ab initio Study. J. Am. Chem. Soc. 1993, 115, 11158-11164.

16. Malekina, S.; Brodbelt, J. High Energy Collision-Induced Dissociation of Alkali Metal Ion Adducts of Crown Ethers and Acyclic Analogs. Rapid Commun. Mass Spectrom. 1992, 6, 376381. 
17. Lattimer, R. P. Tandem Mass Spectrometry of Poly(ethylene glycol) Proton- and Deuteron-Attachment Ions. Int. J. Mass Spectrom. Ion Processes 1992, 116, 23-36.

18. Yanagida, S.; Takahashi, K; Okahara, M. Metal Ion Complexation of Noncyclic Poly(oxyethylene) Derivatives. II: PMR Studies of the Complexation with Alkali and Alkaline Earth Metal Cations. Bull. Chem. Soc. Japan 1978, 51, 1294-1299.

19. Fresdorff, H. K. Stability Constants of Cyclic Polyether Complexes with Univalent Cations. J. Am. Chem. Soc. 1971, 93, 600-606.

20. Pederson, C. J. Cyclic Polyethers and Their Complexes with Metal Salts. J. Am. Chem. Soc. 1967, 89, 7017-7036.

21. Gokel, G. W.; Goli, D. M.; Minganti, C.; Echegoyen, L. Clarification of the Hole-Size Cation-Diameter Relationship in Crown Ethers and a New Method for Determining Calcium Cation Homogeneous Equilibrium Binding Constants. J. Am. Chem. Soc. 1983, 105, 6786-6788.

22. Chu, I.-H.; Zhang, H.; Dearden, D. V. Macrocyclic Chemistry in the Gas Phase: Intrinsic Cation Affinities and Complexation Rates for Alkali Metal Cation Complexes with Crown Ethers and Glymes. J. Am. Chem. Soc. 1993, 115, 5736-5744.

23. Armentrout, P. B. Cation-Ether Complexes in the Gas Phase: Thermodynamic Insight into Molecular Recognition. Int. J. Mass Spectrom. 1999, 193, 227-240.

24. More, M. B.; Ray, D.; Armentrout, P. B. Cation-Ether Complexes in the Gas Phase: Bond Dissociation Energies of $\mathrm{Na}+$ (dimethyl ether) $x, x=1-4 ; \mathrm{Na}+(1,2$-dimethoxyethane) $x, x=$ 1 and 2; and Na + (12-crown-4). J. Phys. Chem. A 1997, 101, 831-839.

25. More, M. B.; Ray, D.; Armentrout, P. B. Cation-Ether Complexes in the Gas Phase: Bond Dissociation Energies of $\mathrm{K}+$ (dimethyl ether) $x, x=1-4 ; \mathrm{K}+(1,2$-dimethoxyethane) $x, x=$ 1 and 2; and K + (12-crown-4). J. Phys. Chem. A 1997, 101, $4254-4262$.

26. More, M. B.; Ray, D.; Armentrout, P. B. Cation-Ether Complexes in the Gas Phase: Bond Dissociation Energies of $\mathrm{Rb}+$ (dimethyl ether) $x, x=1-4 ; \mathrm{Rb}+(1,2$-dimethoxyethane) $x, x=$ 1 and 2; and $\mathrm{Rb}+$ (12-crown-4). J. Phys. Chem. A 1997, 101, 7007-7017.

27. Wyttenbach, T. Von; Heldon, G.; Bowers, M. T. Conformations of Alkali Ion Cationized Polyethers in the Gas Phase: Polyethylene Glycol and Bis [(benzo-15-crown)-15-ylmethyl] Pimelate. Int. J. Mass Spectrom. Ion Processes 1997, 165/166, 377-390.

28. Creaser, C. S.; Griffiths, J. R. Atmospheric Pressure Ion Mobility Spectrometry Studies of Cyclic and Acyclic Polyethers. Anal. Chim. Acta 2001, 436, 273-279.

29. Fenn, J. B.; Mann, M.; Meng, C. K.; Wong, S. F.; Whitehouse, C. M. Electrospray Ionization for Mass Spectrometry of Large Biomolecules. Science 1989, 246, 64-71.

30. Wong, S. F.; Meng, C. K.; Fenn, J. B. Multiple Charging in Electrospray Ionization of Poly(ethylene glycols). J. Phys. Chem. 1988, 92, 546-550.

31. Moyer, B. A. Complexation and Transport. Gokel, G. W., Ed. Molecular Recognition: Receptors for Cationic Guests, Vol. I of Comprehensive Supramolecular Chemistry. Elsevier Sci.: New York, 1996; 377-416.

32. Arakawa, T.; Timasheff, S. N. Mechanism of poly(ethylene glycol) Interaction with Proteins. Biochem. 1985, 24, 6756-6762.

33. Israelachvili, J. The Different Faces of Poly(ethylene glycol). Proc. Nat. Acad. Sci., U.S.A. 1997, 94, 8378-8379.

34. Sheth, S. R.; Leckband, D. Measurement of the Attractive Forces Between Proteins and End-Grafted Poly(ethylene glycol) Chains. Proc. Nat. Acad. Sci. U.S.A. 1997, 94, 8399-8404.

35. Fyles, T. M.; van Straaten-Nijenhuis, W. F. Ion Channel Models. Reinhoudt, D. N., Ed. Supramolecular Chemistry, Vol. X of Comprehensive Supramolecular Chemistry. Elsevier Sci.: New York, 1996; 53-77.
36. McLuckey, S. A.; Cameron, D.; Cooks, R. G. Proton affinities from Dissociations of Proton-Bound Dimers. J. Am. Chem. Soc. 1981, 103, 1313-1317.

37. Cooks, R. G.; Patrick, J. S.; Kotiaho, T.; McLuckey, S. A. Thermochemical Determinations by the Kinetic Method. Mass Spectrom. Rev. 1994, 13, 287-339.

38. Schneider, B. B.; Chen, D. D. Y. Collision Induced Dissociation of Ions within the Orifice-Skimmer Region of an Electrospray Mass Spectrometer. Anal. Chem. 2000, 72, 791-799.

39. Schneider, B. B.; Douglas, D. J.; Chen, D. D. Y. CollisionInduced Dissociation of Bradykinin Ions in the Interface Region of an ESI-MS. J. Am. Soc. Mass Spectrom. 2001, 12, 772-779.

40. McLuckey, S. A.; Van Berkel, G. A.; Goeringer, D. E.; Glish, G. L. Ion Trap Mass Spectrometry of Externally Generated Ions. Anal. Chem. 1994, 66, 689A-696A.

41. Louris, J. N.; Cooks, R. G.; Syka, J. E. P.; Kelly, P. E.; Stafford, G. C.; Todd, J. F. J. Instrumentation, Applications, and Energy Deposition in Quadrupole Ion-Trap Tandem Mass Spectrometry. Anal. Chem. 1987, 59, 1677-1685.

42. Goeringer, D. E.; Whitten, W. B.; Ramsey, J. M.; McLuckey, S. A.; Glish, G. L. Theory of High-Resolution Mass Spectrometry Achieved Via Resonance Ejection in the Quadrupole Ion Trap. Anal. Chem. 1992, 64, 1434-1439.

43. McLuckey, S. A.; Goeringer, D. E. Slow Heating Methods in Tandem Mass Spectrometry. J. Mass Spectrom. 1997, 32, 461474.

44. Splendore, M.; Lausevic, M.; Lausevic, Z.; March, R. E. Resonant Excitation and/or Ejection of Ions Subjected to DC and RF Fields in a Commercial Quadrupole Ion Trap. Rapid Commun. Mass Spectrom. 1997, 11, 228-233.

45. Lammert, S. A.; Cooks, R. G. Surface-Induced Dissociation of Molecular Ions in a Quadrupole Ion Trap Mass Spectrometer. J. Am. Soc. Mass Spectrom. 1991, 2, 487-491.

46. Williams, J. D.; Cooks, R. G.; Syka, J. E. P.; Hemberger, P. H.; Nogar, N. S. Determination of Positions, Velocities, and Kinetic Energies of Resonantly Excited Ions in the Quadrupole Ion Trap Mass Spectrometer by Laser Photodissociation. J. Am. Soc. Mass Spectrom. 1993, 4, 792-797.

47. Williams, J. D.; Cox, K. A.; Cooks, R. G.; McLuckey, S. A.; Hart, K. J.; Goeringer, D. E. Resonance Ejection Ion Trap Mass Spectrometry and Nonlinear Field Contributions: The Effect of Scan Direction on Mass Resolution. Anal. Chem. 1994, 66, 725-729.

48. Louris, J. N.; Amy, J. W.; Ridley, T. Y.; Cooks, R. G. Injection of Ions Into a Quadrupole Ion Trap Mass Spectrometer. Int. J. Mass Spectrom. Ion Processes 1989, 88, 97-111.

49. McLuckey, S. A.; Van Berkel, G. A.; Goeringer, D. E.; Glish, G. L. Ion Trap Mass Spectrometry Using High Pressure Ionization. Anal. Chem. 1994, 66, 737A-743A.

50. McLuckey, S. A.; Goeringer, D. E.; Glish, G. L. Selective Ion Isolation/Rejection Over a Broad Mass Range in the Quadrupole Ion Trap. J. Am. Soc. Mass Spectrom. 1990, 2, 11-21.

51. Julian, R. K.; Cooks, R. G. Broad-Band Excitation in the Quadrupole Ion Trap Mass Spectrometer Using Shaped Pulses Created with the Inverse Fourier Transform. Anal. Chem. 1993, 65, 1827-1833.

52. Kaiser, R. E.; Cooks, R. G.; Moss, J.; Hemberger, P. H. Mass Range Extension in a Quadrupole Ion Trap Mass Spectrometer. Rapid Commun. Mass Spectrom. 1989, 3, 50-53.

53. Schwartz, J. C.; Syka, J. E. P.; Jardine, I. High Resolution on a Quadrupole Ion Trap Mass Spectrometer. J. Am. Soc. Mass Spectrom. 1991, 2, 198-204.

54. Tang, L.; Kebarle, P. Effect of the Conductivity of the Electrosprayed Solution on the Electrospray Current: Factors Determining Analyte Sensitivity in Electrospray Mass Spectrometry. Anal. Chem. 1991, 63, 2709-2715. 
55. Wang, H. J.; Agnes, G. R. Kinetically Labile Equilibrium Shifts Induced by the Electrospray Process. Anal. Chem. 1999, 71, $4166-4172$.

56. Ding, J.; Anderegg, R. J. Specific and Nonspecific Dimer Formation in the Electrospray Ionization Mass Spectrometry of Oligonucleotides. J. Am. Soc. Mass Spectrom. 1994, 6, 159164.

57. Cunniff, J. B.; Vouros, P. False Positives and the Detection of Cyclodextrin Inclusion Complexes by Electrospray Mass Spectrometry. J. Am. Soc. Mass Spectrom. 1995, 6, 437-447.

58. Goeringer, D. E.; Asano, K. G.; McLuckey, S. A. Ion Internal Temperature and Ion Trap Collisional Activation: Protonated Leucine Enkephalin. Int. J. Mass Spectrom. 1999, 182/183, 275288.

59. Cleven, C. D.; Cooks, R. G.; Garrett, A. W.; Nogar, N. S.; Hemberger, P. H. Radial Distributions and Ejection Times of Molecular Ion in an Ion Trap Mass Spectrometer: A Laser Tomography Study of Effects of Ion Density and Molecular Type. J. Phys. Chem. 1996, 100, 40-46.

60. Plass, W. R.; Gill, L. A.; Bui, H. A.; Cooks, R. G. Ion Mobility Measurement by dc Tomography in an rf Quadrupole Ion Trap. J. Phys. Chem. A 2000, 104, 5059-5065.

61. Mathurin, J.-C.; Gregoire, S.; Brunot, A.; Tabet, J.-C.; March, R. E.; Catinella, S.; Traldi, P. Investigation of Space Charge Interqactions Which Arise During Simultaneous Confinement of Positive and Negative Ions in an Ion Trap Mass Spectrometer. J. Mass Spectrom. 1997, 32, 829-837.

62. Chan, K. W. S.; Cook, K. D. Mass Spectrometric Study of Interactions Between Poly(ethylene glycols) and Alkali Metals in Solution. Macromolecules 1983, 16, 1736-1740.
63. Chan, K. W. S.; Cook, K. D. Factors Affecting Mass Spectral Sensitivity for Ions Sampled by Field Evaporation from a Liquid Matrix. Anal. Chem. 1983, 55, 1306-1309.

64. Cook, K. D.; Chan, K. W. S. Energy Deposition in Desorption Ionization. Int. J. Mass Spectrom. Ion Process 1983, 54, 135-149.

65. von Velden, G.; Wyttenbach, T.; Bowers, M. T. Conformation of Macromolecules in the Gas Phase: Use of Matrix-Assisted Laser Desorption Methods in Ion Chromatography. Science 1995, 267, 1483-1485.

66. Goeringer, D. E.; McLuckey, S. A. Relaxation of Internally Excited High-Mass Ions Simulated Under Typical Quadrupole Ion Trap Storage Conditions. Int. J. Mass Spectrom. 1998, 177, 163-174.

67. Liere, P.; Blasco, T.; March, R. E.; Tabet, J. C. Influence of Cooling Time on the Internal Energy of Ions Subjected to Resonance Excitation in a Quadrupole Ion Trap. Rapid Commun. Mass Spectrom. 1994, 8, 953-956.

68. Liere, P.; Steiner, V.; Jennings, K. R.; March, R. E.; Tabet, J. C. Influence of Ion Activation and Thermalization Effects on Reaction Rate Constants in a Quadrupole Ion Trap Mass Spectrometer. Int. J. Mass Spectrom. Ion Process 1997, 167/168, 735-751.

69. Liu, Y.; Valetine, S. J.; Counterman, A. E.; Hoaglund, C. S.; Clemmer, D. E. Injected-Ion Mobility Analysis of Biomolecules. Anal. Chem. 1997, 69, 728A-735A.

70. Srebalus, C. A.; Li, J.; Marshall, W. S.; Clemmer, D. E. Gas Phase Separations of Electropsrayed Peptide Libraries. Anal. Chem. 1999, 71, 3918-3927.

71. Melsh, M. F.; Hunter, J. M.; Shvartsburg, A. A.; Schatz, G. C.; Jarrold, M. F. Structural Information from Ion Mobility Measurements. J. Phys. Chem. 1996, 100, 16082-16086. 